\title{
Effect of His-Tag on Expression, Purification, and Structure of Zinc Finger Protein, ZNF191(243-368)
}

\author{
Dongxin Zhao ${ }^{1}$ and Zhongxian Huang ${ }^{2}$ \\ ${ }^{1}$ School of Chemistry and Chemical Engineering, Henan University of Technology, Zhengzhou 450001, China \\ ${ }^{2}$ Department of Chemistry, Fudan University, Shanghai 200433, China \\ Correspondence should be addressed to Dongxin Zhao; zhaodx798@163.com
}

Received 18 April 2016; Revised 13 June 2016; Accepted 23 June 2016

Academic Editor: Viktor Brabec

Copyright (c) 2016 D. Zhao and Z. Huang. This is an open access article distributed under the Creative Commons Attribution License, which permits unrestricted use, distribution, and reproduction in any medium, provided the original work is properly cited.

Zinc finger proteins are associated with hereditary diseases and cancers. To obtain an adequate amount of zinc finger proteins for studying their properties, structure, and functions, many protein expression systems are used. ZNF191(243-368) is a zinc finger protein and can be fused with His-tag to generate fusion proteins such as His ${ }_{6}$-ZNF191(243-368) and ZNF191(243-368)-His . The $^{-}$ purification of His-tag protein using Ni-NTA resin can overcome the difficulty of ZNF191(243-368) separation caused by inclusion body formation. The influences of His-tag on ZNF191(243-368) properties and structure were investigated using spectrographic techniques and hydrolase experiment. Our findings suggest that insertion of a His-tag at the N-terminal or C-terminal end of ZNF191(243-368) has different effects on the protein. Therefore, an expression system should be considered based on the properties and structure of the protein. Furthermore, the hydrolase activity of ZNF191(243-368)- $\mathrm{His}_{8}$ has provided new insights into the design of biological functional molecules.

\section{Introduction}

Protein properties, structure, and functions are important considerations for the expression of proteins in vitro. Although proteins can be expressed in vitro using various expression systems, the formation of inclusion body, toxicity of exogenous proteins, modification of side-chain, and so forth all influence protein expression and can complicate the process of protein purification. Therefore, it has been difficult to express enough proteins for studying them in vitro. This also presents challenges for studying on ZNF191 and ZNF191(243-368).

Fusion expression systems (e.g., GST and His-tag) can facilitate protein expression and simplify protein purification $[1,2]$. However, each expression system has unique characteristics that affect how it can be used. For example, if the target protein contains a thrombin digestion site, it cannot be easily cut from the GST fusion protein and cannot be expressed using the GST system. The His-tag expression systems are widely used because His-tags have a low molecular weight and do not affect protein structure and functions. This means that it is not necessary to separate the His-tag from the target protein $[3,4]$. Moreover, His-tag fusion proteins can easily be purified by Ni-NTA affinity resin. Zinc finger proteins have been expressed, separated, and purified using the Histag/Ni-NTA system [4-6]. However, the use of His-tag fusion proteins remains controversial $[7,8]$.

We established two His-tag expression systems for

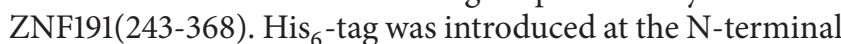
end and $\mathrm{His}_{8}$-tag was introduced at the $\mathrm{C}$-terminal end of ZNF191(243-368). Ni-NTA resin was used for protein purification, which overcame the difficulty of ZNF191(243368) separation and purification caused by the formation of inclusion body. The effects of the His-tag on ZNF191(243-368) properties and structure were evaluated using spectrographic techniques and hydrolase activity experiment. Our findings have furthered our understanding of the structure and folding processes of the zinc finger protein. 


\section{Materials and Methods}

2.1. Materials. Restriction enzymes, BamH I, Hind III, Nde I, and Xho I, and T4 DNA ligase were purchased from New England Biolabs. Pfu DNA polymerase, dNTPs, isopropyl $\beta$-Dthiogalactoside (IPTG), Triton X-100, imidazole, ampicillin, and kanamycin were purchased from Sangon (Shanghai, China). Ni-NTA resin was purchased from Qiagen. All other reagents were of analytical grade. The pET-41b plasmid and Escherichia coli BL21(DE3) strain, pQE30 plasmid, and M15 strain (Novagen) were used as expression vectors and host strains. The pGEX-B plasmid was constructed in our lab. YM5 ultrafiltration membrane was from Amicon. Sephadex G-25 was purchased from Pharmacia Biotech. Low- and mid-range protein markers were obtained from Bio Basic Inc.

2.2. Construction of Recombinant Plasmids. The pQE-ZF plasmid was constructed as previously described for expressing $\mathrm{His}_{6}-\mathrm{ZNF191(243-368)}$ [9]. The primers used to construct the ZNF191(243-368)-His ${ }_{8}$ expression system were as follows: up-primer: $5^{\prime}$-GGAATTCCATATGAGAAATCCCTCTCGAAAGAAACA-3'; down-primer: $5^{\prime}$ CCGCTCGAGAACTTCCACAACATTCAGAAG-3'. These primers were used to amplify ZNF191(243-368) from the pTSA-18 plasmid. Each segment was digested using Nde I and Xho I endonucleases and inserted into pET-41b vector. The resulting vector was named $\mathrm{pET}-\mathrm{ZF}$ and transformed into E. Coli BL21(DE3) strain for expression.

2.3. Expression and Purification of His-Tagged ZNF191(243368). Plasmids pQE-ZF and pET-ZF were transformed into E. coli M15 and E. coli BL21(DE3) host bacteria, respectively. For His-tag expression systems, $3 \mathrm{~mL}$ of LB medium containing appropriate antibiotics (for the $\mathrm{His}_{6}$-tag expression system, ampicillin and kanamycin were added; for $\mathrm{His}_{8}$-tag expression system, kanamycin was added) was inoculated with a freshly isolated bacterial colony of the host strain carrying a recombinant vector. The medium was incubated overnight at $37^{\circ} \mathrm{C}$ and diluted to $1: 100$ in $3 \mathrm{~mL}$ of LB medium containing antibiotics with shaking until $\mathrm{OD}_{600}=0.6$; then IPTG was added at different concentrations and cultures were grown at different temperatures for different time. Cells of $1 \mathrm{~mL}$ medium grown and induced under different conditions were centrifugated and resuspended in $1 \mathrm{~mL}$ of lysate buffer, then mixed with $1 \mathrm{~mL}$ of $2 \times$ SDS loading buffer, and boiled for $10 \mathrm{~min}$, so the samples of whole cells were prepared. Then all samples were run on $15 \%$ SDS-PAGE gel and visualized by Coomassie Brilliant Blue R-250 staining. The target proteins were detected by comparison with protein standard markers, and the optimum conditions for in vitro expression were determined.

High expression of proteins was induced under optimum conditions. The expression and purification of ZNF191(243368)- $\mathrm{His}_{8}$ were similar to those of $\mathrm{His}_{6}$-ZNF191(243-368) [9]. The cells harvested from $500 \mathrm{~mL}$ of LB medium grown and induced under the optimum conditions were suspended in 10 volumes of cell lysis buffer $\left(50 \mathrm{mmol} \cdot \mathrm{L}^{-1} \mathrm{NaH}_{2} \mathrm{PO}_{4}, \mathrm{pH}\right.$ 8.0, $300 \mathrm{mmol} \cdot \mathrm{L}^{-1} \mathrm{NaCl}$, and $5 \mathrm{mmol} \cdot \mathrm{L}^{-1}$ imidazole). And cells were lysed by lysozyme for about $1 \mathrm{~h}$ at $4^{\circ} \mathrm{C}$, then treated with $5 \mathrm{U} / \mathrm{mL}$ DNase, and stirred for $30 \mathrm{~min}$ to degenerate nucleic acids at $4^{\circ} \mathrm{C}$. Soluble and insoluble cell fractions were separated by centrifugation at $15,000 \mathrm{r} / \mathrm{min}$ for $30 \mathrm{~min}$. Supernatants were mixed with Ni-NTA resin to purify fusion proteins according to manufacturer's manual. His-tagged proteins were eluted in the elution containing $50 \mathrm{mmol} \cdot \mathrm{L}^{-1}$ $\mathrm{NaH}_{2} \mathrm{PO}_{4}, 300 \mathrm{mmol} \cdot \mathrm{L}^{-1} \mathrm{NaCl}$, and $250 \mathrm{mmol} \cdot \mathrm{L}^{-1}$ imidazole, at $\mathrm{pH}$ 8.0. The eluted solution was concentrated using Amicon YM-5 and then passed through a Sephadex G75 column to get rid of impurities and a Sephadex G-25 column to remove salts; then collected protein solution was lyophilized. The purified proteins were mixed with $2 \times$ SDS loading buffer and boiled for $10 \mathrm{~min}$ to prepare the samples. The samples were detected by $15 \%$ SDS-PAGE gel.

2.4. UV-Vis Absorption Spectroscopy. The UV spectra of proteins were recorded on a HP 8453 Diode Array spectrophotometer (USA). Protein concentrations in $10 \mathrm{mM}$ Tris- $\mathrm{HCl}$ solution ( $\mathrm{pH}$ 7.5) were determined using Bradford's method. The concentration was $1 \mu \mathrm{mol} \cdot \mathrm{L}^{-1}$.

2.5. Circular Dichroism (CD) Spectroscopy. CD spectra of proteins were recorded between 190 and $250 \mathrm{~nm}$ using a J720 Jasco spectropolarimeter. The optical path length was $10 \mathrm{~mm}$, and the concentration of protein solution with $10 \mathrm{mM}$ Tris$\mathrm{HCl}(\mathrm{pH} 7.5)$ was $1 \mu \mathrm{mol} \cdot \mathrm{L}^{-1}$. The recordings were conducted at $25^{\circ} \mathrm{C}$.

2.6. Zinc Ion Titration Test. ZNF191(243-368) and ZNF191(243-368) with His-tag were acidified and filtered through a Sephadex G-25 column to obtain proteins without zinc ions. CD curves of the zinc-free protein titrated by zinc ions were tested.

2.7. Urea Degeneration Test. A series of buffer solutions with different final urea concentrations $(0,1,2,3,4,5,6,7$, and $\left.8 \mathrm{~mol} \cdot \mathrm{L}^{-1}\right)$ were prepared. The same protein amounts were added to all buffer solutions, which were let to stand for $10 \mathrm{~min}$ at room temperature to measure fluorescence.

2.8. Hydrolase Activity Test. Different amounts of protein solutions were added to the plasmid solution to give a final protein concentration of $1 \mu \mathrm{mol} \cdot \mathrm{L}^{-1}$. They were tested by $1 \%$ agarose gel electrophoresis after $24 \mathrm{~h}$ at $37^{\circ} \mathrm{C}$.

\section{Results and Discussion}

3.1. Construction of Recombinant Plasmids. Plasmid pQE-30 has six continuous His codes at the $\mathrm{N}$-terminal end of the exogenous gene and has ampicillin resistance. BamH I and Hind III digestion sites were used to clone the ZNF191(243368) gene into the pQE-30 plasmid, producing the plasmid pQE-ZF. A RGS-His ${ }_{6}$ code is present behind the initiation codon of $\mathrm{pQE}-\mathrm{ZF}$, and the amino acid residues Gly and Ser are encoded by the BamH I site following the Histag; therefore protein expressed by $\mathrm{pQE}-\mathrm{ZF}$ contains eleven additional amino acid residues (RGSHHHHHHGS) at the Nterminal end of ZNF191(243-368). The expressed protein is called $\mathrm{His}_{6}$-ZNF191(243-368), and it has a molecular weight 


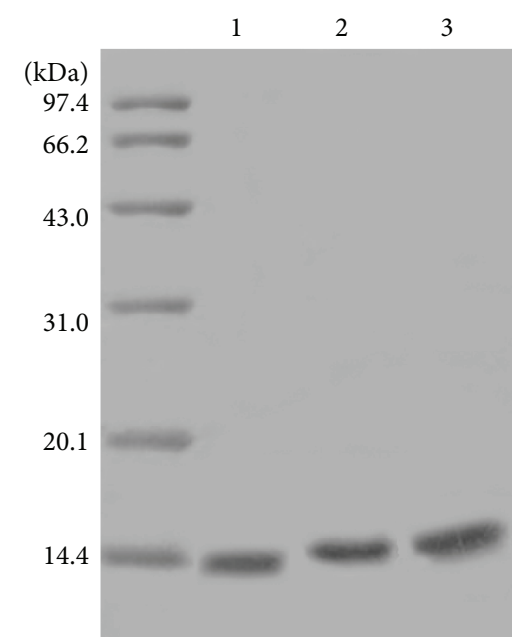

FIGURE 1: SDS-PAGE of zinc finger proteins. Lane 1: ZNF191(243368), lane 2: $\mathrm{His}_{6}$-ZNF191(243-368), and lane 3: ZNF191(243-368)$\mathrm{His}_{8}$.

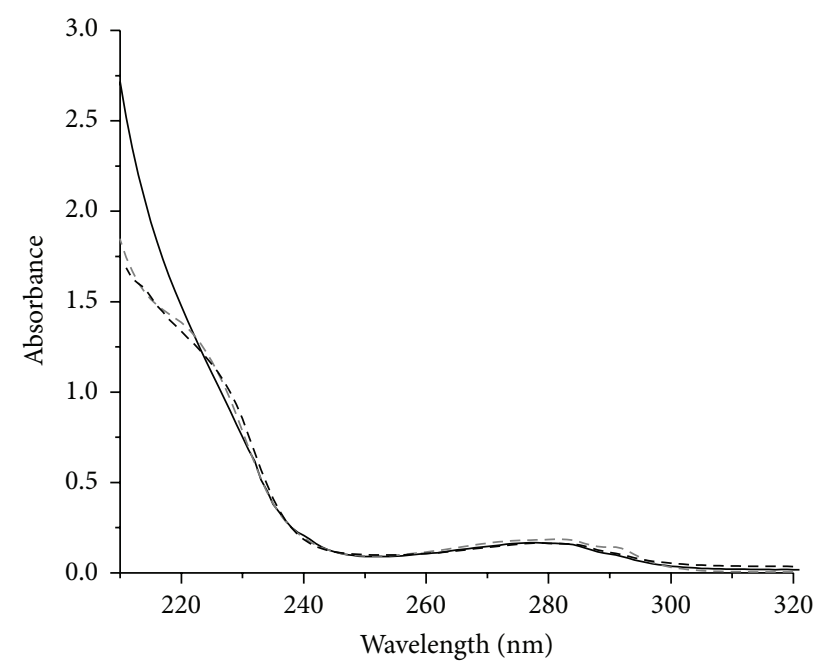

Figure 2: UV spectra of zinc finger proteins. Dark dashed line is ZNF191(243-368), gray dashed line is $\mathrm{His}_{6}$-ZNF191(243-368), and dark solid line is ZNF191(243-368)-His .

1267 Da higher than that of ZNF191(243-368). In the plasmid pET-41b, the target gene was cloned between the Nde I and Xho I sites, generating a recombinant plasmid pET-ZF. Since the recognition site of Nde I has an initiation codon, no additional amino acid residues are present at the $\mathrm{N}$-terminal end of ZNF191(243-368). However, the amino acid residues Leu and Glu are encoded by the recognition site of Xho I before eight continuous histidines; therefore an additional ten amino acid residues (LEHHHHHHHH) were detected at the $\mathrm{C}$-terminal end of the target protein. The expressed protein is ZNF191(243-368)-His 8 and has a molecular weight $1339 \mathrm{Da}$ higher than ZNF191(243-368).

3.2. Expression and Purification of Proteins. The proteins were expressed under optimum conditions: the bacteria were grown to $\mathrm{OD}_{600}=0.6$ at $37^{\circ} \mathrm{C}$ and then induced by $0.1 \mathrm{mM}$

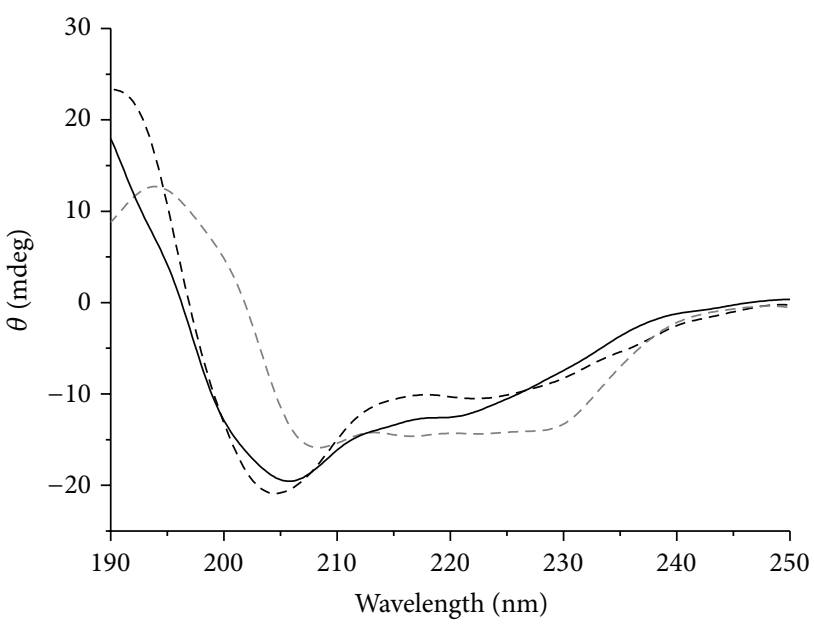

FIgURE 3: CD spectra of zinc finger proteins. Dark dashed line is ZNF191(243-368), gray dashed line is $\mathrm{His}_{6}$-ZNF191(243-368), and dark solid line is ZNF191(243-368)-His .

IPTG for $6 \mathrm{~h}$. His-tagged proteins were purified using NiNTA resin and detected by SDS-PAGE.

Although the molecular weights of $\mathrm{His}_{6}$-ZNF191(243368 ) and ZNF191(243-368)- $\mathrm{His}_{8}$ are higher than that of ZNF191(243-368), the difference between molecular weights was not observable by SDS-PAGE. The corresponding proteins showed a single band (Figure 1), indicating that the protein purity was higher than $90 \%$ and the position of the electrophoretic band was consistent with the expected molecular weight of the proteins. This indicated that target proteins were obtained in vitro, and His-tag expression systems were suitable for expressing and purifying ZNF191(243-368).

3.3. UV Spectra of Proteins. In UV spectra of the three proteins (Figure 2), no significant difference was observed. All have absorption peaks of Phe and Tyr at $260-280 \mathrm{~nm}$ as well as the shoulder peak of the $\mathrm{Zn}-\mathrm{S}$ bond formed by cysteine- $\mathrm{Zn}^{2+}$ coordinating at $230 \mathrm{~nm}$, indicating that these proteins likely have similar structures $[10,11]$.

3.4. CD Spectra of Proteins. According to the CD spectra of proteins in the far UV region (Figure 3), ZNF191(243-368) shows typical negative absorption peaks of an $\alpha$-helix at about $205 \mathrm{~nm}$ and $222 \mathrm{~nm}$ as well as a positive absorption peak at about $190 \mathrm{~nm}$ [12]. The positive absorption peak shifted to $195 \mathrm{~nm}$, and three shoulder peaks of negative peak at 210-230 nm in the CD spectrum of $\mathrm{His}_{6}$-ZNF191(243-368) indicated that $\mathrm{His}_{6}$-ZNF191(243-368) had more $\beta$-folding [13]. In addition, the similarity between the $\mathrm{CD}$ spectra of ZNF191(243-368)-His ${ }_{8}$ and ZNF191(243-368) showed that they had a similar structure. This indicated that the His-tags at the $\mathrm{C}$-terminal end and $\mathrm{N}$ - terminal end of the zinc finger protein ZNF191(243-368) have different effects.

3.5. Zinc Ion Titration Test. Coordination of zinc ions with Cys and His in zinc finger peptides to form a tetrahedral molecule is necessary for maintaining the structure of the zinc finger domain. The CD spectrum is an effective means 


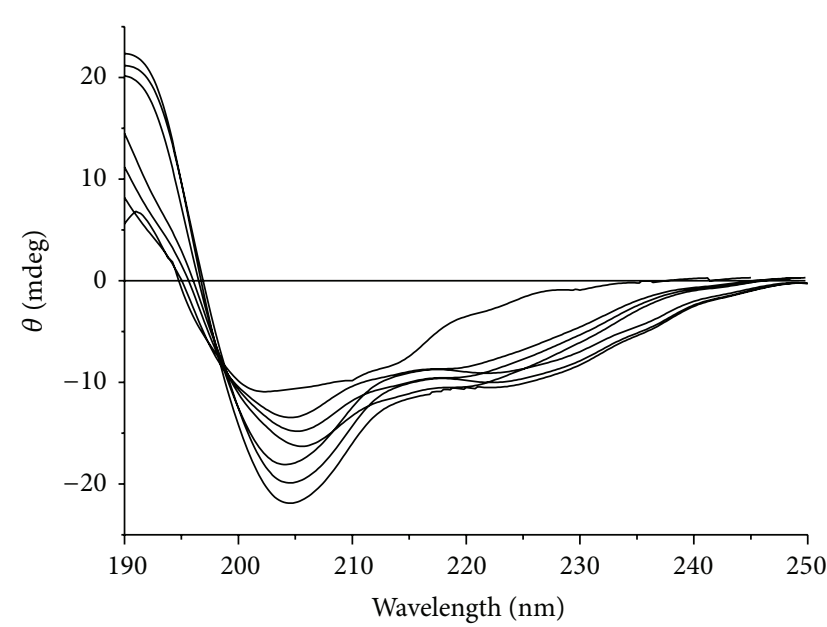

(a)

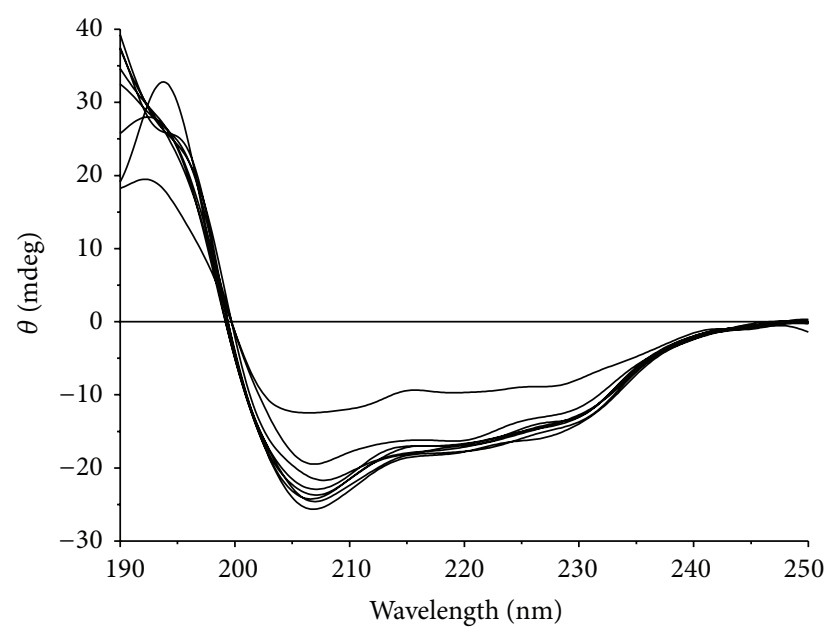

(b)

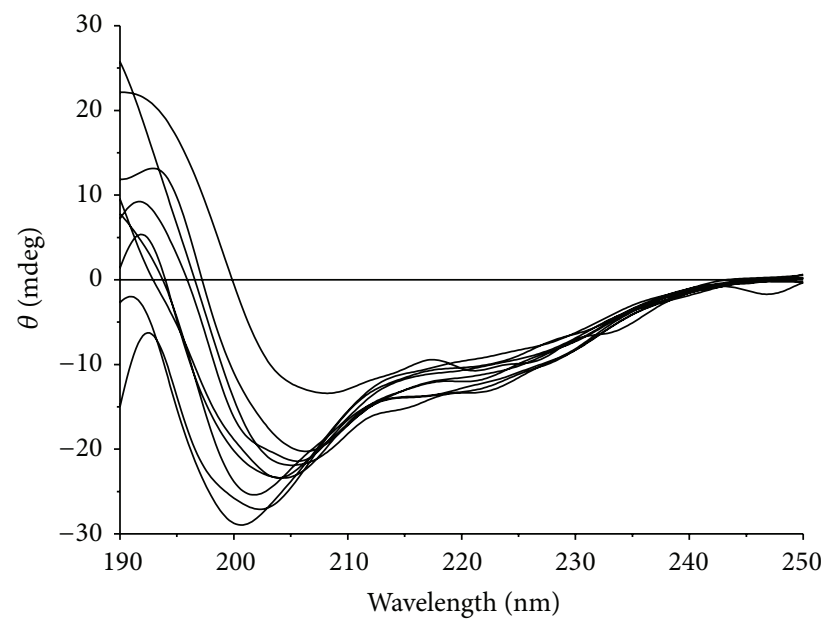

(c)

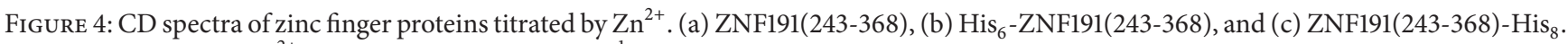
The concentration of $\mathrm{Zn}^{2+}$ is from 0 (up) to $10 \mu \mathrm{mol} \cdot \mathrm{L}^{-1}$ (down).

to test the folding of the zinc finger depending on the zinc ion coordination. The structure of the zinc finger domain is destroyed by dezincification and can be recovered by the addition of zinc ions; therefore zinc ions facilitate folding of the zinc finger peptide chain.

The CD spectra of zinc-free protein titrated with zinc ions are shown in Figure 4. These show that zinc-free zinc finger proteins have a positive peak at about $190 \mathrm{~nm}$ and a negative peak at 205-235 nm, demonstrating that zinc-free zinc finger proteins still maintain some secondary structure and do not completely change into an irregular curve [14]. The addition of zinc ions returns the CD spectra of zinc-free ZNF191(243368) and zinc-free $\mathrm{His}_{6}$-ZNF191(243-368) to those of proteins before dezincification shown in Figure 3. This indicates that their structure can be recovered by the addition of zinc ions [15]. In the zinc ion titration curve of zinc-free ZNF191(243$368)-\mathrm{His}_{8}$, the negative peak of an $\alpha$-helix at about $208 \mathrm{~nm}$ shifted to $200 \mathrm{~nm}$, which is similar to the negative peak of the irregular curve at about $200 \mathrm{~nm}$, indicating that ZNF191(243-

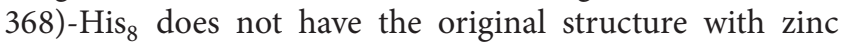

ion coordination because eight continuous histidines at the C-terminal end hinder the normal coordination of peptide chain with zinc ions.

Viewed from the perspective of inorganic chemistry, two ligands at the carboxyl end of one domain and two ligands at the amino end of the next domain may coordinate with one zinc ion in a protein containing continuous $\mathrm{C}_{2} \mathrm{H}_{2}$ zinc finger domains. Furthermore, two peptide chains may coordinate with one zinc ion [16]. The difference in the CD spectra of ZNF191(243-368)-His ${ }_{8}$ whether before or after zinc titration is caused by metal mismatching of His-tag at the C-terminal end. Of course, these are only speculations based on CD spectra. We hope to determine the structures of these proteins in the future through NMR and their crystal structure.

3.6. Urea Degeneration Test. ZNF191(243-368) contains four tyrosines. After urea degeneration, the microenvironment of tyrosines in proteins will be changed, so the fluorescence spectra of proteins will be varied accordingly to manifest changes of the protein structure [17, 18]. Displacement 


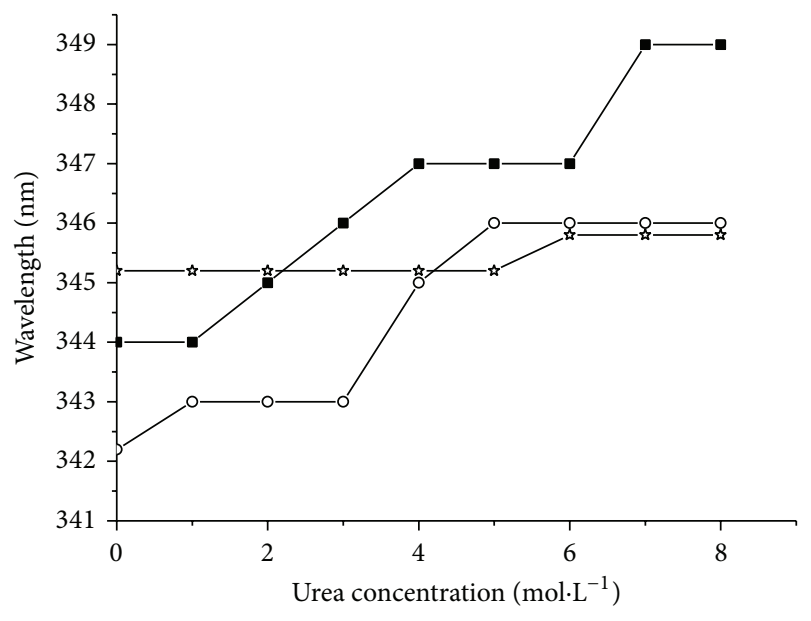

FIGURE 5: Urea denaturation-emission wavelength maximum versus

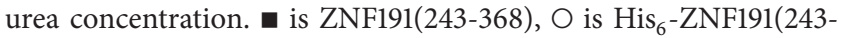
368), and is is ZNF191(243-368)-His.

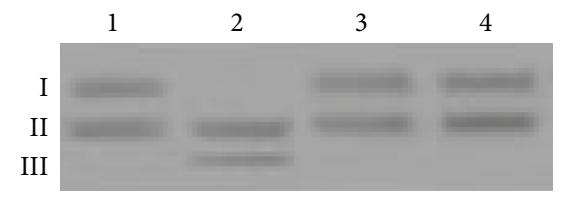

FIGURE 6: Cleavage of the plasmid DNA by zinc finger proteins. Lane 1 is pGEX-B not containing proteins, lane 2 is pGEX-B containing ZNF191(243-368)-His ${ }_{8}$, lane 3 is pGEX-B containing His $_{6}$ ZNF191(243-368), and lane 4 is pGEX-B containing ZNF191(243368).

variations of the maximum emission wavelength of different zinc finger proteins under different urea concentrations are shown in Figure 5. The unfolding of proteins under different urea concentrations was analyzed based on the fluorescence spectra.

Under low urea concentrations, the maximum emission peak wavelength of the fluorescence spectrum of ZNF191(243-368) was about $344 \mathrm{~nm}$, which shifted to $350 \mathrm{~nm}$ with increasing urea concentration. The maximum emission peak wavelength of $\mathrm{His}_{6}$-ZNF191(243-368) shifted from 342 to $346 \mathrm{~nm}$. The maximum emission peak wavelength of the fluorescence spectrum of ZNF191(243-368) and $\mathrm{His}_{6}$ ZNF191(243-368) had the same red shift, suggesting that tyrosine residues in the protein moved from the original nonpolar environment in folding proteins to the polar environment in unfolding proteins. This was in accordance with the structure of zinc finger proteins. Since tyrosine in ZNF191(243-368) is the key amino acid residue of the hydrophobic core in the classical "finger-like" structure, it is exposed in solvent gradually during protein unfolding [19]. However, the maximum wavelength of ZNF191(243-368)-His ${ }_{8}$ did not change as the urea concentration increased, implying that the environment of tyrosine was changed slightly during unfolding. Therefore, His-tags at the $\mathrm{N}$-terminal end and C-terminal end of proteins influence the structure of ZNF191(243-368) in different ways. Whether this difference influences protein functions remains to be elucidated.

3.7. Hydrolase Activity Test. The special hydrolysis of the phosphate ester linkage in DNA by natural nucleases has been a problem. Artificial design of hydrolytic nucleases will contribute more identifiable DNA sequences, which will benefit medicine design and gene therapy. At present, most design strategies are to connect DNA binding elements and DNA lipolytic elements or build up an active site of hydrolase in DNA binding peptides [20-22]. Many zinc finger proteins recognize specific DNA sequences. New zinc finger proteins have been designed to recognize unique DNA sequences and extend the recognition length of DNA [23-25]. It would be useful if a nuclease with a zinc finger structure could be designed, because the recognized site of zinc finger domain is not a symmetric sequence. The Cys in SP1 was mutated to His to successfully develop a zinc finger peptide with DNA hydrolysis function [26]. This reminds us of whether hydrolytic activity will be introduced into the zinc finger peptide or zinc finger protein through His-tag. Here, we chose plasmid pGEX-B containing a GGAGGG site to study the hydrolytic activity of His-tagged proteins. The pGEX-B plasmid was obtained from the DNA binding experiment of ZNF191(243-368) [27], and the electrophoresis results were shown in Figure 6. The plasmids all had two main bands.

Generally, extracted plasmids have two, sometimes three, electrophoretic bands. The plasmid at superhelix state (I) moved the quickest, followed by the ring plasmid (II) and the line plasmid (III) [28]. Line structure was developed and superhelix plasmids dissociated completely when ZNF191(243-368)-His ${ }_{8}$ was added. This indicated that coordination of His and zinc ions endowed the protein with DNA pyrolysis. This may explain why $\mathrm{H}_{4}$-zinc finger structures do not exist in living body. But this is not available in $\mathrm{His}_{6}$ ZNF191(243-368), which further confirmed that different positions of polyhistidine will have different effects. Polyhistidine at the $\mathrm{C}$-terminal end of the zinc finger protein may be easier to form activity site similar in protease [29].

\section{Conclusions}

His-tags at the $\mathrm{N}$-terminal end and $\mathrm{C}$-terminal end of ZNF191(243-368) have different influences on the properties and structure of proteins. Therefore, it is necessary to consider carefully whether to choose His-tag system for in vitro expression of zinc finger proteins. ZNF191(243-368) with Histag had different properties, which provided new insights into the design of biological functional molecules.

\section{Competing Interests}

The authors declare that there is no conflict of interests regarding the publication of this paper.

\section{Acknowledgments}

The authors would like to acknowledge the financial supports from the National Natural Science Foundation of China 
(no. 21301050 and no. 21575034) and the Scientific and Technological Project of Henan Province (162102210197).

\section{References}

[1] K. M. Khoo, C. F. Chang, J. Schubert, E. Wondrak, and H. H. Chng, "Expression and purification of the recombinant Histagged GST-CD38 fusion protein using the baculovirus/insect cell expression system," Protein Expression and Purification, vol. 40, no. 2, pp. 396-403, 2005.

[2] C. Croci, J. H. Brandstätter, and R. Enz, “ZIP3, a new splice variant of the $\mathrm{PKC}-\zeta$-interacting protein family, binds to GABAC receptors, $\mathrm{PKC}-\zeta$, and $\mathrm{Kv} \beta 2$," The Journal of Biological Chemistry, vol. 278, no. 8, pp. 6128-6135, 2003.

[3] A. B. Mason, Q.-Y. He, T. E. Adams et al., "Expression, purification, and characterization of recombinant nonglycosylated human serum transferrin containing a C-terminal hexahistidine tag," Protein Expression and Purification, vol. 23, no. 1, pp. 142-150, 2001.

[4] H. Z. Peng, G. E. Begg, S. L. Harper, J. R. Friedman, D. W. Speicher, and F. J. Rauscher III, "Biochemical analysis of the Krüppel-associated box (KRAB) transcriptional repression domain," The Journal of Biological Chemistry, vol. 275, no. 24, pp. 18000-18010, 2000.

[5] G. D. Meredith, H. Y. Wu, and N. L. Allbritton, "Targeted protein functionalization using his-tags," Bioconjugate Chemistry, vol. 15, no. 5, pp. 969-982, 2004.

[6] S. Sharpe, W.-M. Yau, and R. Tycko, "Expression and purification of a recombinant peptide from the Alzheimer's $\beta$ amyloid protein for solid-state NMR," Protein Expression and Purification, vol. 42, no. 1, pp. 200-210, 2005.

[7] A. B. Mason, Q.-Y. He, P. J. Halbrooks et al., "Differential effect of a His tag at the N- and C-termini: functional studies with recombinant human serum transferrin," Biochemistry, vol. 41, no. 30, pp. 9448-9454, 2002.

[8] A. Chant, X. Provatopoulou, I. W. Manfield, and G. G. Kneale, "Structural and functional characterisation of the DNA binding domain of the Aspergillus nidulans gene regulatory protein AreA," Biochimica et Biophysica Acta (BBA)-Proteins and Proteomics, vol. 1648, no. 1-2, pp. 84-89, 2003.

[9] D.-X. Zhao, X.-C. Teng, Z.-C. Ding, and Z.-X. Huang, "Expression and purification of ZNF191(243-368) in three expression systems," Chinese Journal of Chemistry, vol. 25, no. 11, pp. 17391742, 2007.

[10] L.-C. Chen, M. E. Noelken, and H. Nagase, "Disruption of the cysteine-75 and zinc ion coordination is not sufficient to activate the precursor of human matrix metalloproteinase 3 (stromelysin 1)," Biochemistry, vol. 32, no. 39, pp. 10289-10295, 1993.

[11] W. F. Li, J. Zhang, J. Wang, and W. Wang, "Metal-coupled folding of $\mathrm{Cys}_{2} \mathrm{His}_{2}$ zinc-finger," Journal of the American Chemical Society, vol. 130, no. 3, pp. 892-900, 2008.

[12] R. W. Driver, H. N. Hoang, G. Abbenante, and D. P. Fairlie, "A cyclic $\beta$-strand tripeptide with an a-helix like CD spectrum," Organic Letters, vol. 11, no. 14, pp. 3092-3095, 2009.

[13] D. M. Rothwarf, P.-T. Shi, J.-L. Peng, H. A. Scheraga, and V. G. Davenport, "Use of sequence-specific tri-block copolymers to determine the helix-forming tendencies of amino acids," Biopolymers, vol. 39, no. 4, pp. 531-536, 1996.

[14] X. Chen, M. Chu, and D. P. Giedroc, "MRE-binding transcription factor-1: weak zinc-binding finger domains 5 and 6 modulate the structure, affinity, and specificity of the metalresponse element complex," Biochemistry, vol. 38, no. 39, pp. 12915-12925, 1999.

[15] T. Pan and J. E. Coleman, "Structure and function of the $\mathrm{Zn}$ (II) binding site within the DNA-binding domain of the GAL4 transcription factor," Proceedings of the National Academy of Sciences of the United States of America, vol. 86, no. 9, pp. 31453149, 1989.

[16] K. R. Thickman, A. Davis, and J. M. Berg, "Site selection in tandem arrays of metal-binding domains," Inorganic Chemistry, vol. 43, no. 25, pp. 7897-7901, 2004.

[17] G. Mei, A. D. Venere, A. F. Agrò, F. D. Matteis, and N. Rosato, "Dipolar relaxation times of tryptophan and tyrosine in glycerol and in proteins: a direct evaluation from their fluorescence decays," Journal of Fluorescence, vol. 13, no. 6, pp. 467-477, 2003.

[18] A. M. Jones Brunette and D. L. Farrens, "Distance mapping in proteins using fluorescence spectroscopy: tyrosine, like tryptophan, quenches bimane fluorescence in a distance-dependent manner," Biochemistry, vol. 53, no. 40, pp. 6290-6301, 2014.

[19] A. Chant, C. M. Kraemer-Pecore, R. Watkin, and G. G. Kneale, "Attachment of a histidine tag to the minimal zinc finger protein of the Aspergillus nidulans gene regulatory protein AreA causes a conformational change at the DNA-binding site," Protein Expression and Purification, vol. 39, no. 2, pp. 152-159, 2005.

[20] S. J. Franklin, "Lanthanide-mediated DNA hydrolysis," Current Opinion in Chemical Biology, vol. 5, no. 2, pp. 201-208, 2001.

[21] E. Boseggia, M. Gatos, L. Lucatello et al., "Toward efficient $\mathrm{Zn}$ (II)-based artificial nucleases," Journal of the American Chemical Society, vol. 126, no. 14, pp. 4543-4549, 2004.

[22] R. T. Kovacic, J. T. Welch, and S. J. Franklin, "Sequence-selective DNA cleavage by a chimeric metallopeptide," Journal of the American Chemical Society, vol. 125, no. 22, pp. 6656-6662, 2003.

[23] M. Nagaoka, Y. Doi, J. Kuwahara, and Y. Sugiura, "Novel strategy for the design of a new zinc finger: creation of a zinc finger for the AT-rich sequence by $\alpha$-helix substitution," Journal of the American Chemical Society, vol. 124, no. 23, pp. 6526-6527, 2002.

[24] T. Kamiuchi, E. Abe, M. Imanishi, T. Kaji, M. Nagaoka, and Y. Sugiura, "Artificial nine zinc-finger peptide with 30 base pair binding sites," Biochemistry, vol. 37, no. 39, pp. 13827-13834, 1998.

[25] M. Papworth, P. Kolasinska, and M. Minczuk, "Designer zincfinger proteins and their applications," Gene, vol. 366, no. 1, pp. 27-38, 2006.

[26] A. Nomura and Y. Sugiura, "Sequence-selective and hydrolytic cleavage of DNA by zinc finger mutants," Journal of the American Chemical Society, vol. 126, no. 47, pp. 15374-15375, 2004.

[27] D. X. Zhao and Z. X. Huang, "Recognition code of ZNF191(243368 ) and its interaction with DNA," Bioinorganic Chemistry and Applications, vol. 2015, Article ID 416751, 7 pages, 2015.

[28] K. Lu, J. Sun, D.-X. Zhao, Q.-C. Zhu, and W. Lv, "The synthesis of L-dopa-L-Tyr and the interaction of L-dopa-L-Tyr with ctDNA," International Journal of Peptide Research and Therapeutics, vol. 20, no. 3, pp. 299-305, 2014.

[29] B. L. Vallee and D. S. Auld, "Cocatalytic zinc motifs in enzyme catalysis," Proceedings of the National Academy of Sciences of the United States of America, vol. 90, no. 7, pp. 2715-2718, 1993. 

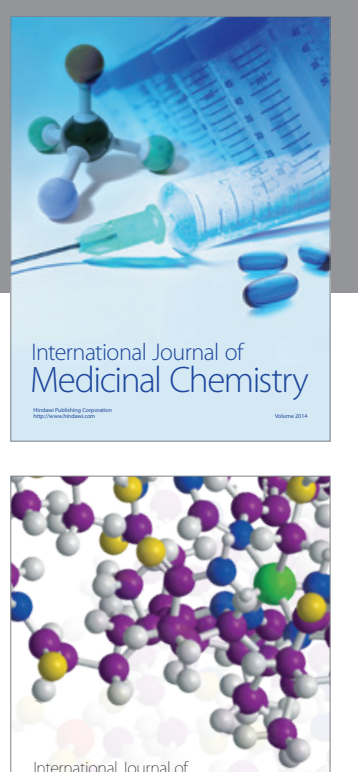

Carbohydrate Chemistry

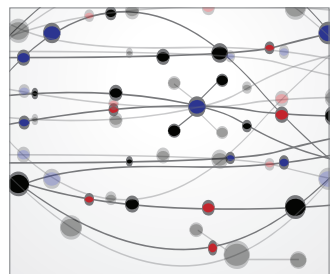

The Scientific World Journal
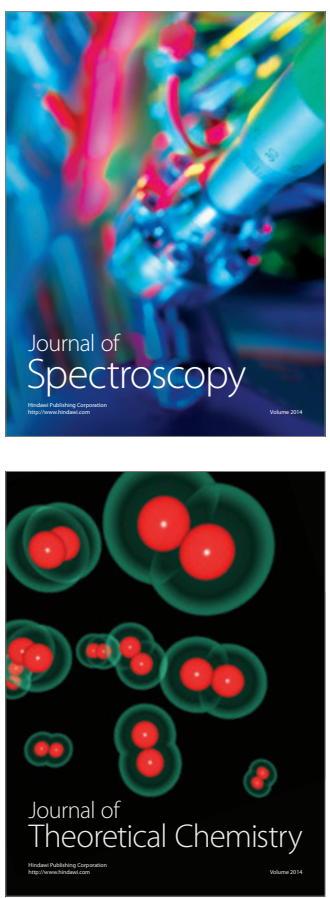
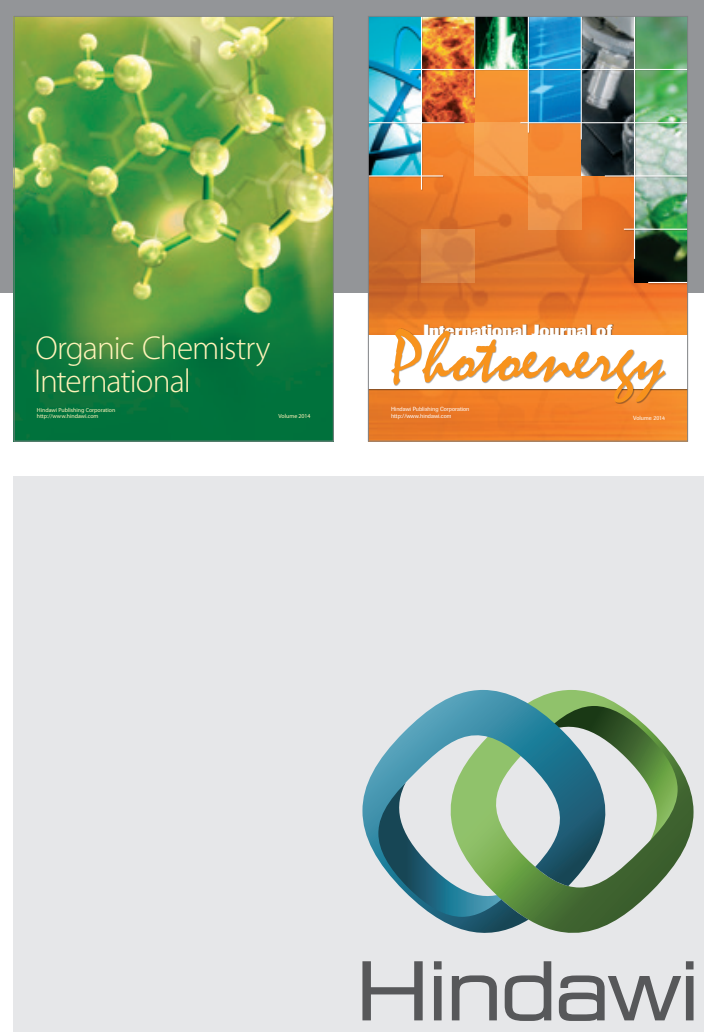

Submit your manuscripts at

http://www.hindawi.com

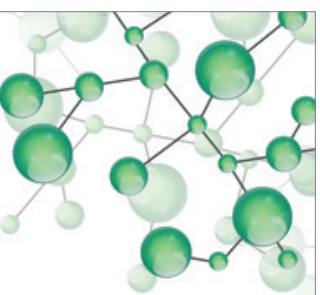

International Journal of

Inorganic Chemistry

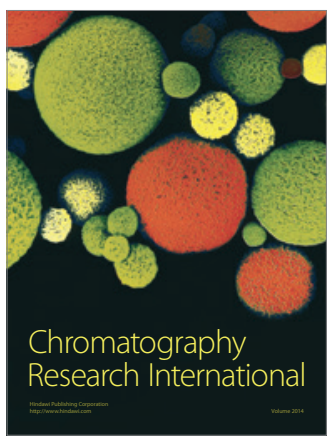

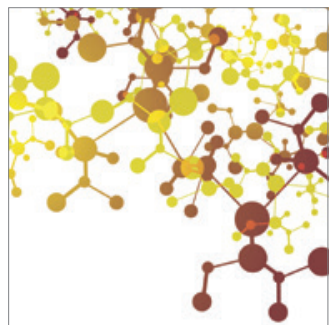

Applied Chemistry
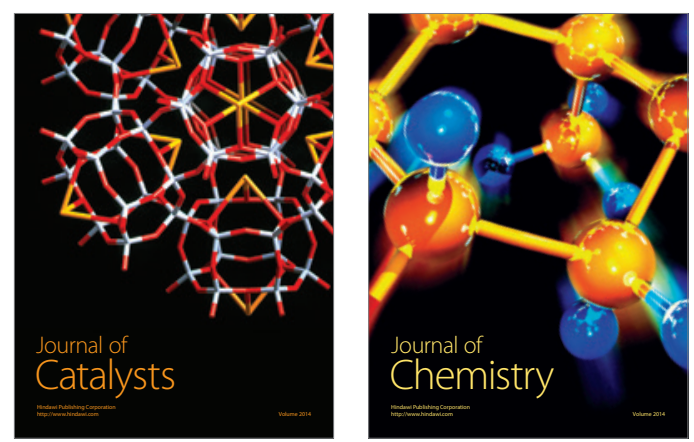
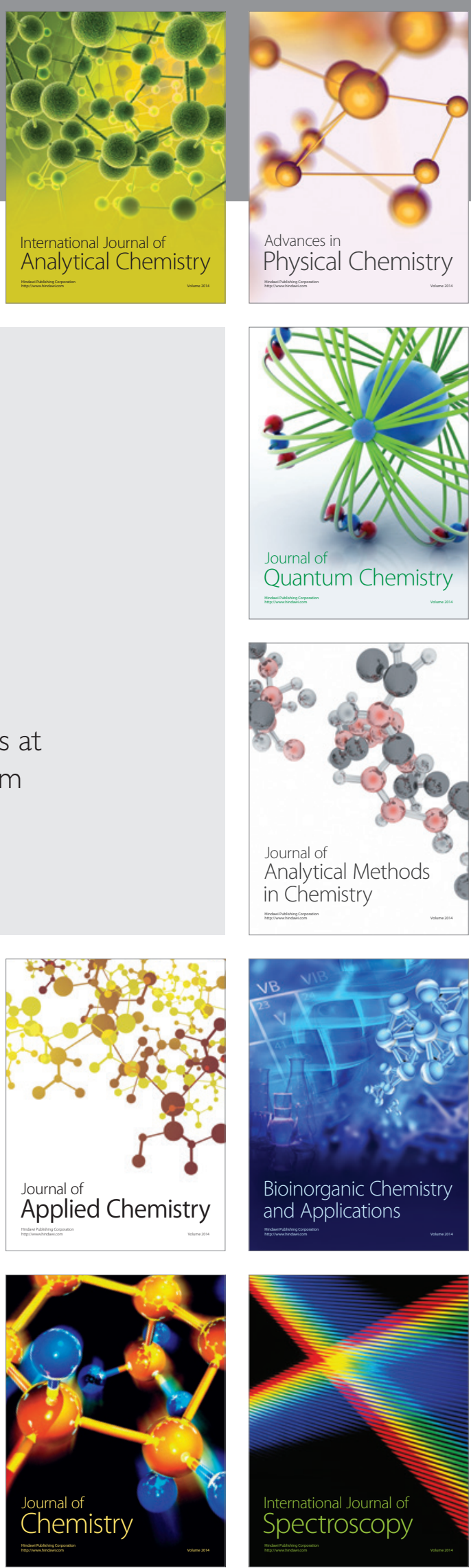